\title{
Effectiveness of anti-osteoporotic treatment after successful parathyroidectomy for primary hyperparathyroidism: a randomized, double-blind, placebo-controlled trial
}

\author{
Martin B. Niederle ${ }^{1,2}$ (D) Ursula Foeger-Samwald ${ }^{3} \cdot$ Philipp Riss $^{1} \cdot$ Andreas Selberherr $^{1} \cdot$ Christian Scheuba $^{1}$. \\ Peter Pietschmann ${ }^{3} \cdot$ Bruno Niederle $^{1} \cdot$ Katharina Kerschan-Schindl $^{4}$
}

Received: 13 March 2019 / Accepted: 16 August 2019/Published online: 26 August 2019

(C) The Author(s) 2019

\begin{abstract}
Purpose After successful surgery for primary hyperparathyroidism, bone mineral density (BMD) does not improve equally in all patients. As no trial has so far aimed to influence normalization of BMD, it was the goal of this investigation to determine whether pharmacological treatment is effective in improving regain of BMD after successful parathyroidectomy in patients with preoperatively diagnosed osteoporosis or osteopenia and to evaluate when treatment may be indicated.

Methods In this randomized, placebo-controlled, double-blind trial, 52 patients were treated with strontium ranelate $2 \mathrm{~g}$ daily + $1000 \mathrm{mg}$ calcium + $800 \mathrm{IU}$ vitamin D (strontium group; SG) or with $1000 \mathrm{mg}$ calcium + $800 \mathrm{IU}$ vitamin D alone (placebo group; PG) for 1 year. The main outcome measures were BMD (lumbar spine, femoral neck, radius) and bone turnover markers.

Results The baseline characteristics were similar in both groups. Absolute BMD $\left(1.007 \pm 0.197 \mathrm{vs} .0 .897 \pm 0.137 \mathrm{~g} / \mathrm{cm}^{2} ; p=\right.$ $0.024)$ and both relative $(9.94$ vs. $3.94 \% ; p<0.001)$ and absolute $\left(0.09 \pm 0.06\right.$ vs. $\left.0.03 \pm 0.04 \mathrm{~g} / \mathrm{cm}^{2} ; p<0.001\right)$ changes in lumbar-spine BMD were significantly higher in the SG than in the PG. Compared to baseline, BMD significantly increased in both groups at the lumbar spine ( $p<0.001$ and $p=0.001$, respectively) and femoral neck (both $p<0.001$ ), whereas radius BMD only changed significantly in the SG. However, the proportion of patients with osteoporosis/osteopenia significantly declined only at the lumbar spine in the SG (from 69.0 to $37.9 \% ; p=0.034$ ), whereas no decrease was found in the PG. No severe adverse events occurred.

Conclusions Postoperative anti-osteoporotic treatment can positively influence regain of BMD mainly in the lumbar spine and should be considered. Without treatment, most patients and especially those with low preoperative markers of bone turnover remained osteoporotic/osteopenic 1 year after surgery.
\end{abstract}

Keywords Primary hyperparathyroidism $\cdot$ Parathyroidectomy $\cdot$ Bone mineral density $\cdot$ Osteoporosis $\cdot$ Biomarkers

Electronic supplementary material The online version of this article (https://doi.org/10.1007/s00423-019-01815-9 ) contains supplementary material, which is available to authorized users.

Martin B. Niederle

martin.niederle@meduniwien.ac.at

1 Department of Surgery, Division of General Surgery, Medical University of Vienna, Waehringer Guertel 18-20, 1090 Vienna, Austria

2 Department of Anesthesia, General Intensive Care and Pain Management, Medical University of Vienna, Waehringer Guertel 18-20, 1090 Vienna, Austria
3 Department of Pathophysiology and Allergy Research, Center for Pathophysiology, Infectiology and Immunology, Medical University of Vienna, Waehringer Guertel 18-20, 1090 Vienna, Austria

4 Department of Physical Medicine, Rehabilitation and Occupational Medicine, Medical University of Vienna, Waehringer Guertel 18-20, 1090 Vienna, Austria 


\section{Introduction}

Primary hyperparathyroidism (pHPT) affects bone metabolism by advancing turnover through increase in both bone formation and resorption, resulting in a net decrease in bone mineral density (BMD) and strength $[1,2]$. In the literature, the incidence of osteopenia or osteoporosis in patients with pHPT has been estimated at 39\% to 59\%, affecting BMD at all sites measured (lumbar spine, femur, and radius) [3-5]. The fracture risk, especially in vertebral spine, is thus increased up to fivefold [6-8] and is associated with low BMD [9]. Parathyroidectomy (PTX) is the only causal treatment for pHPT and is recommended even in patients without severe symptoms, yet reduced BMD [10].

Only three randomized trials have addressed the effect of PTX on BMD vs. observation alone. PTX resulted in a minor but significant increase in BMD of $0.5 \%$ to $4 \%$ after 1 year $[11,12]$ and a $3.3 \%$ increase only at the lumbar spine after 5 years [13] in patients with mild disease. Improvement of $\mathrm{BMD}$ is not found in all patients, as another prospective trial showed no improvement whatsoever following PTX in more than half of postmenopausal women [14]. Thus, the fracture risk is increased by up to 10 or more years following successful surgery $[6,15,16]$. No investigations have so far focused on patients with $\mathrm{pHPT}$ and preoperatively diagnosed osteoporosis or osteopenia, who generally are at an advanced risk of fractures, especially not for their postoperative change in BMD and bone turnover.

To our knowledge, no trial has as yet addressed the potentially positive influence of treatment with anti-osteoporotic medication on BMD and bone metabolism after PTX. Basically, these medications can have two physiological effects: they either reduce bone resorption or increase bone formation. While the main effect of bisphosphonate therapy is the reduction of bone resorption, it seems more reasonable to stimulate bone formation to advance the increase in BMD after PTX. Strontium ranelate (SR) is one of the few osteoporosis-specific medications that both stimulate osteoblasts and thereby bone formation and inhibit osteoclasts (reducing bone resorption) [17, 18], leading to a decrease in vertebral and non-vertebral fractures $[19,20]$. A metaanalysis of four trials has substantiated the positive effect of $2 \mathrm{~g}$ SR daily on the fracture risk in primary osteoporosis [21], [22]. Improved bone microarchitecture [23] may at least partially account for this effect.

Although the use of SR has been restricted (for the potentially elevated risk of thromboembolism and cardiovascular events), it at least continues to serve as an example of an anti-osteoporotic medication for patients with low BMD after successful PTX. The rationale is to stimulate bone formation, re-improve bone strength, increase BMD to the largest extent and as quickly as possible, and thus potentially prevent fractures.
Another new target of pharmacological intervention to increase bone formation is the Wnt signaling pathway, measured by the biochemical parameters sclerostin (SOST) and Dickkopf-1 (DKK-1). Although there is evidence that this pathway is important for the effects of parathyroid hormone (PTH) on bone metabolism [24], the dynamics of SOST and DKK-1 after PTX for PHPT have not yet been investigated. This pathway is of special interest, as the novel therapeutic agent romosozumab, an antibody against SOST, has shown potent anti-osteoporotic effects [25].

Thus, the aim of this study was to focus on osteopenic and osteoporotic patients after PTX for pHPT in an attempt to investigate the effect of an anti-osteoporotic medication with an anabolic effect on the change of BMD and on classical biochemical markers of bone metabolism. Additionally, the parameters SOST and DKK-1 were analyzed as potential future targets of intervention for stimulating bone formation.

\section{Materials and methods}

\section{Patients}

All postmenopausal women and men with biochemically proven $\mathrm{pHPT}$ and osteopenia (T-score $\leq 1$ and $\geq 2.5$ ) or osteoporosis (T-score $\leq 2.5$ ) according to WHO criteria [26] consulting the Department of Surgery, Medical University of Vienna, were asked to participate in this study prior to PTX. Following the recently published guidelines for the diagnosis and definitive management of pHPT, all patients fulfilled the criteria for surgical intervention [10, 27-29].

The exclusion criteria before surgery included anamnestic pulmonary embolism or deep venous thrombosis, blood coagulation disorder or coagulopathy, phenylketonuria, renal impairment (creatinine clearance $<30 \mathrm{~mL} / \mathrm{h}$ ), severe hepatic disorder, severe systemic disorder, thyroid dysfunction, and immobilization. Additionally, the intake of drugs with potential effects on BMD, such as glucocorticoids, lithium, estrogen replacement therapy, selective estrogen receptor modulators, bisphosphonates (oral: last 3 months, parenteral: past year), and denosumab (past year), was not allowed. The patients were excluded after surgery in the case of malignant disease (thyroid or parathyroid cancer, except for microcarcinoma of the thyroid gland), persistent or recurrent pHPT (postoperative hypercalcemia), four-gland hyperplasia, multiple endocrine neoplasia, hereditary pHPT, or familial hypocalcuric hypercalcemia (calcium/creatinine ratio $<0.01$ ). In accordance with European Medicines Agency regulations, additional exclusion criteria (ischemic cardiac disease, peripheral arterial obstructive disease, cerebrovascular disease, and uncontrolled arterial hypertonia) were introduced in April 2013. Since then, electrocardiograms have been included in prestudy screening and were also performed after the 12-month study period. 
The study procedures of this double-blind, placebo-controlled, randomized trial were approved by the Ethics Committee of the Medical University of Vienna (EKNr: 2142008), the Austrian Agency for Health and Food Safety (Österreichische Agentur für Gesundheit und Ernährungssicherheit), ClinicalTrials.gov (identifier: NCT01222026), and European Union Drug Regulating Authorities Clinical Trials. All study participants gave written informed consent in accordance with the Declaration of Helsinki.

\section{Study design and treatment protocol}

PTX was performed according to the current indications for surgery $[10,27]$. Within 1 week after surgery, all enrolled patients received daily supplements of $1000 \mathrm{mg}$ of calcium and $800 \mathrm{IU}$ of vitamin D. Four weeks after surgery, the patients were randomly assigned to be given placebo (placebo group; PG) or SR 2 g daily (strontium group; SG) for 1 year (sequentially numbered containers). The primary outcome variable was BMD at the lumbar spine. The secondary outcome parameters were BMD at other sites and biochemical parameters.

\section{BMD}

The BMD measurements at the lumbar spine, left femoral neck, and non-dominant radius (one-third distal [1/3 radius], mid-distal [MID radius], and ultradistal [UD radius]) were performed using a dual-energy X-ray absorption (DXA) device (HOLOGIC 4500; Hologic Inc., Waltham, MA, USA; coefficient of variation: $2 \%$ ). All measurements were conducted using the standard procedures recommended by the manufacturer. The BMD values are expressed as $\mathrm{g} / \mathrm{cm}^{2}$ and $\mathrm{T}$ scores.

\section{Biochemical parameters}

Overnight fasting venous blood samples were taken before surgery, 4 weeks, and 3, 6, and 12 months after surgery. Routine parameters $\left(\mathrm{PTH}\right.$, ionized calcium $\left[\mathrm{Ca}^{++}\right]$, phosphate, 25-hydroxyvitamin D [25(OH)D], 1,25-dihydroxyvitamin D $[1,25(\mathrm{OH}) \mathrm{D}])$ were determined using standard methods. Additionally, bone turnover markers were studied: bonespecific alkaline phosphatase (BAP; Liaison Analyzer, DiaSorin Inc., Stillwater, MN, USA; detection limit: $0.1 \mu \mathrm{g} / \mathrm{L}$; intra-assay coefficient of variation: $3.3-4.3 \%$, inter-assay coefficient of variation: $6.1-8.1 \%$ ), osteocalcin (OC; Cobas 8000 Analyzer, Roche Diagnostics, Rotkreuz, Switzerland; detection limit: $0.01 \mathrm{ng} / \mathrm{mL}$; intra-assay coefficient of variation: $0.9-1.3 \%$, inter-assay coefficient of variation: 1.2-2.3\%), and CrossLaps (CTX; Cobas 8000 Roche Analyzer, Roche Diagnostics, Rotkreuz, Switzerland; detection limit: $0.5 \mathrm{ng} / \mathrm{mL}$; intra-assay coefficient of variation: $1.2-4.7 \%$, inter-assay coefficient of variation: $1.5-5.7 \%$ ). Serum was frozen at $-70{ }^{\circ} \mathrm{C}$ until analysis for osteoprotegerin (OPG, BI-20403; colorimetric sandwich immunoassays, Biomedica, Vienna, Austria; detection limit: $0.07 \mathrm{pmol} / \mathrm{L}$; intra-assay coefficient of variation: $\leq 3 \%$, inter-assay coefficient of variation: $\leq 5 \%$, according to the manufacturer's data), receptor activator of nuclear factor-kappa B ligand (RANKL, BI-20452; colorimetric sandwich immunoassays, Biomedica, Vienna, Austria; detection limit: $0.02 \mathrm{pmol} / \mathrm{L}$; intra-assay coefficient of variation: $\leq 9 \%$; inter-assay coefficient of variation: $\leq 6 \%$, according to the manufacturer's data), SOST (BI-20492; colorimetric sandwich immunoassays, Biomedica, Vienna, Austria; detection limit: $2.6 \mathrm{pmol} / \mathrm{L}$; intra-assay coefficient of variation: $\leq 5 \%$; inter-assay coefficient of variation: $\leq 6 \%$, according to the manufacturer's data), and DKK-1 (BI-20412; colorimetric sandwich immunoassays, Biomedica, Vienna, Austria; detection limit: $0.38 \mathrm{pmol} / \mathrm{L}$; intra-assay coefficient of variation: $\leq 8.0 \%$, inter-assay coefficient of variation: $\leq 12.0 \%$, according to the manufacturer's data).

\section{Statistical analysis}

Normal distribution was assessed with the Shapiro-Wilk test and visual inspection of histograms. After descriptive analysis, parametric tests ( $t$ test for baseline characteristics and BMD) and non-parametric tests (Wilcoxon's rank-sum test for biochemical parameters) were used for group comparison. In order to compare the two time points, longitudinal changes within each group were evaluated with the paired $t$ test (BMD) or the Wilcoxon's signed rank test (biochemical parameters). Fisher's exact test was used to test for differences in binominal proportions. As the sample size was inadequate for the Chisquare test of homogeneity, Fisher's exact test was also applied to test for differences in multinomial distributions. Spearman's rank order correlation was run to assess the relationship between the increase in BMD and preoperative biochemical parameters.

Data are given as mean ( \pm standard deviation $[\mathrm{SD}])$ or median (25th quartile; 75 th quartile). $P$ values $<0.05$ were considered significant.

\section{Sample size}

The sample size was calculated in cooperation with the Institute of Medical Statistics, Medical University of Vienna, to provide a statistical power of $80 \%$ accepting an alpha error of $5 \%$. Background data were taken from the literature. The 1year treatment effect of SR was estimated as 3\% BMD change in the lumbar spine. The SD in the literature was $\pm 3.7 \%[19$, 20]. Thirty patients were to be recruited in each group (including an estimated $20 \%$ loss of follow-up). 
Fig. 1 Flow diagram of screening, randomization, and completion

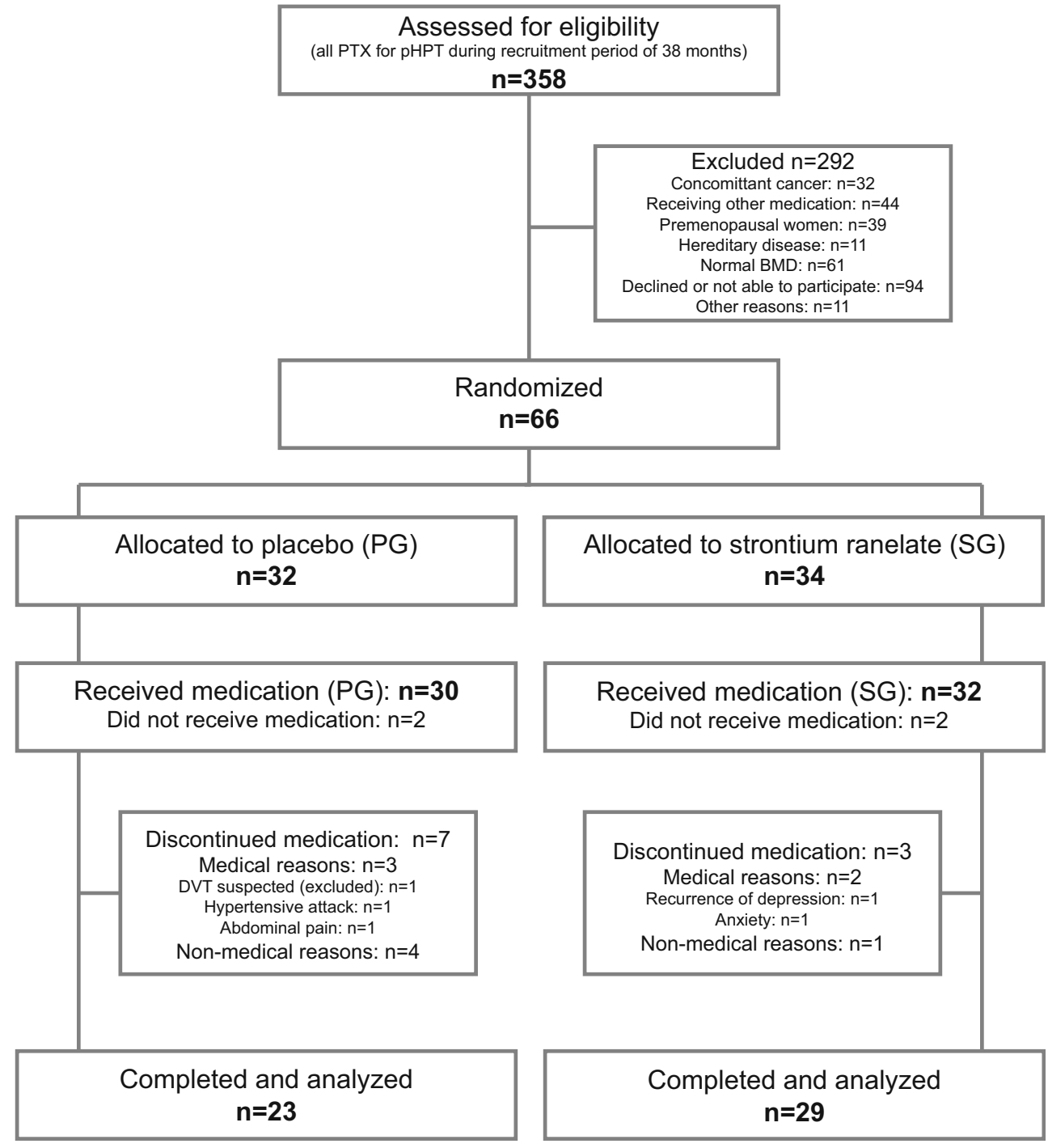

\section{Results}

\section{Baseline parameters}

Of the 358 patients who underwent PTX due to biochemically proven $\mathrm{pHPT}$ at our institution during the study period, 291 were ineligible or not interested in participating (Fig. 1). Four of the 66 randomly assigned subjects (SG: 34; PG: 32) were excluded before they received medication because of hypercalcemia and intolerance of calcium supplementation. The study medication was finally administered to 62 patients. Patient withdrawals were due to medical reasons (SG: 2; PG: 3), protocol violations (PG: 2), and nonmedical reasons (SG: 1; PG: 2). Thus, 29 patients in the SG and 23 in the PG were included in the statistical analysis (per protocol).

Of these 52 patients, 8 had typical and 44 only minor or no symptoms of pHPT. Open minimally invasive PTX (OMIP) was performed in 20 patients, unilateral exploration for PTX in 8 patients, and bilateral exploration for PTX in 24 patients.
In most cases $(n=50)$, histological analysis revealed an adenoma of the parathyroid gland; only two patients had hyperplasia.

The baseline characteristics were similar and did not differ significantly between the groups. There were no surgical complications (Table 1).

\section{Change in BMD}

At the lumbar spine, absolute BMD after 1 year was higher in the SG than in the PG $\left(1.007 \pm 0.197 \mathrm{~g} / \mathrm{cm}^{2}\right.$ vs. $0.897 \pm$ $\left.0.137 \mathrm{~g} / \mathrm{cm}^{2} ; p=0.024\right)$. Additionally, the percentage change of BMD after 1 year was more than twofold higher in the SG than in the PG (9.94 vs. 3.94\%; $p<0.001)$. Also, the absolute BMD change was significantly higher in the SG $(0.09 \pm$ $0.06 \mathrm{~g} / \mathrm{cm}^{2}$ vs. $\left.0.03 \pm 0.04 \mathrm{~g} / \mathrm{cm}^{2} ; p<0.001\right)$. At all other sites, both the percentage and absolute changes in BMD were higher in the SG but did not reach the level of significance (Table 2). 
Table 1 Baseline characteristics; mean $( \pm \mathrm{SD})$ or median $(25$ th percentile; 75 th percentile)

\begin{tabular}{|c|c|c|c|}
\hline & Placebo group $(n=23)$ & Strontium group $(n=29)$ & $p$ \\
\hline Gender f/m & $16 / 7$ & $16 / 13$ & \\
\hline \multicolumn{4}{|l|}{ Type of operation } \\
\hline OMIP & 10 & 11 & \\
\hline Unilateral exploration & 2 & 6 & \\
\hline Bilateral exploration & 11 & 12 & \\
\hline \multicolumn{4}{|l|}{ Surgical complications } \\
\hline Bleeding & 0 & 0 & \\
\hline Recurrent nerve palsy & 0 & 0 & \\
\hline Age (years) & $63( \pm 10)$ & $63( \pm 12)$ & 0.949 \\
\hline Height (cm) & $168( \pm 8)$ & $170( \pm 10)$ & 0.481 \\
\hline Weight (kg) & $76( \pm 15)$ & $80( \pm 16)$ & 0.388 \\
\hline BMI & $27.1( \pm 4.8)$ & $27.8( \pm 4.4)$ & 0.561 \\
\hline Baseline BMD lumbar spine $\left(\mathrm{g} / \mathrm{cm}^{2}\right)$ & $0.864( \pm 0.134)$ & $0.917( \pm 0.185)$ & 0.260 \\
\hline Baseline T-score lumbar spine & $-1.8( \pm 1.2)$ & $-1.4( \pm 1.5)$ & 0.300 \\
\hline Baseline BMD femoral neck $\left(\mathrm{g} / \mathrm{cm}^{2}\right)$ & $0.680( \pm 0.123)$ & $0.686( \pm 0.114)$ & 0.867 \\
\hline Baseline T-score femoral neck & $-1.6( \pm 1.1)$ & $-1.7( \pm 0.9)$ & 0.953 \\
\hline Baseline BMD 1/3 radius $\left(\mathrm{g} / \mathrm{cm}^{2}\right)$ & $0.585(0.085)$ & $0.605( \pm 0.088)$ & 0.410 \\
\hline Baseline $T$-score $1 / 3$ radius & $-2.4( \pm 1.2)$ & $-2.4( \pm 1.0)$ & 0.821 \\
\hline Baseline BMD MID radius $\left(\mathrm{g} / \mathrm{cm}^{2}\right)$ & $0.512( \pm 0.077)$ & $0.520( \pm 0.080)$ & 0.718 \\
\hline Baseline T-score MID radius & $-2.3( \pm 1.2)$ & $-2.4( \pm 1.0)$ & 0.815 \\
\hline Baseline BMD UD radius $\left(\mathrm{g} / \mathrm{cm}^{2}\right)$ & $0.396( \pm 0.091)$ & $0.390( \pm 0.077)$ & 0.805 \\
\hline Baseline T-score UD radius & $-1.6( \pm 1.1)$ & $-1.7( \pm 0.9)$ & 0.601 \\
\hline PTH $(\mathrm{pg} / \mathrm{mL})$ & $123.9(90.8 ; 162.2)$ & $141.3(97.4 ; 162.9)$ & 0.747 \\
\hline $\mathrm{Ca}^{++}(\mathrm{mmol} / \mathrm{L})$ & $1.39(1.36 ; 1.43)$ & $1.41(1.38 ; 1.50)$ & 0.264 \\
\hline Phosphate (mmol/L) & $0.70(0.57 ; 0.83)$ & $0.64(0.57 ; 0.74)$ & 0.342 \\
\hline 25(OH)D (nmol/L) & $38.9(26.8 ; 47.4)$ & $39.8(29.8 ; 52.1)$ & 0.719 \\
\hline $1,25(\mathrm{OH}) \mathrm{D}(\mathrm{nmol} / \mathrm{L})$ & $62.0(49.0 ; 77.0)$ & $64.0(54.0 ; 96.0)$ & 0.612 \\
\hline $\mathrm{BAP}(\mathrm{ng} / \mathrm{mL})$ & $20.4(14.6 ; 28.3)$ & $15.9(10.8 ; 27.7)$ & 0.339 \\
\hline OC (ng/mL) & $41.8(22.8 ; 59.6)$ & $33.2(25.2 ; 43.3)$ & 0.315 \\
\hline CTX (ng/mL) & $0.84(0.42 ; 1.01)$ & $0.63(0.52 ; 0.79)$ & 0.325 \\
\hline P1NP (ng/mL) & $61.5(47.0 ; 89.0)$ & $52.0(43.0 ; 74.5)$ & 0.482 \\
\hline $24 \mathrm{~h} \mathrm{CrCl}(\mathrm{mL} / \mathrm{min})$ & $107.7(96.4 ; 132.8)$ & $121.6(89.4 ; 161.5)$ & 0.768 \\
\hline Patients with $24 \mathrm{~h} \mathrm{CrCl}<60 \mathrm{~mL} / \min (n)$ & 0 & $2^{\mathrm{a}}$ & \\
\hline $\mathrm{OPG}(\mathrm{pmol} / \mathrm{L})$ & $4.46(3.64 ; 5.64)$ & $4.65(3.63 ; 5.47)$ & 0.869 \\
\hline RANKL (pmol/L) & $0.87(0.51 ; 1.42)$ & $0.74(0.52 ; 0.99)$ & 1 \\
\hline SOST (pmol/L) & $19.63(15.55 ; 29.31)$ & $20.84(14.85 ; 28.49)$ & 0.934 \\
\hline DKK-1 (pmol/L) & $25.10(18.99 ; 35.69)$ & $32.32(23.71 ; 41.04)$ & 0.129 \\
\hline
\end{tabular}

${ }^{\text {a }}$ Both patients had a $24 \mathrm{~h} \mathrm{CrCl}$ of $>60 \mathrm{~mL} / \mathrm{min} 1$ year after surgery

OMIP open minimally invasive parathyroidectomy, $B M I$ body mass index, $B M D$ bone mineral density, $1 / 3$ radius one-third distal radius, MID radius Mid-distal radius, $U D$ radius ultradistal radius, $P T H$ parathyroid hormone, $\mathrm{Ca}^{++}$ionized calcium, 25(OH)D 25-hydroxyvitamin D, 1,25(OH)D 1,25-dihydroxyvitamin D, BAP bonespecific alkaline phosphatase, $O C$ osteocalcin, $C T X$ CrossLaps, $P 1 N P$ procollagen type $1 \mathrm{~N}$-terminal propeptide, $24 \mathrm{~h} \mathrm{CrCl}$ measured 24-h creatinine clearance, $O P G$ osteoprotegerin, $R A N K L$ receptor activator of nuclear factorkappa B ligand, SOST sclerostin, DKK-1 Dickkopf-1
Comparing baseline and 1-year controls in both the SG and the PG, there was a significant increase in BMD at the lumbar spine (both $p<0.001)$ and the femoral neck $(p<0.001$ and $p=0.001$ ). Radius BMD (except $1 / 3$ radius) changed significantly in the SG only ( $p=0.008$ and 0.009 , respectively)
(Fig. 2, Supplementary Data 1). Both the percentages and absolute changes did not differ significantly between female and male patients, neither in the SG nor in the PG.

When summing up osteoporosis and osteopenia, the percentage of lumbar-spine disorders before treatment 
Table 2 Relative changes $(\Delta)$ in BMD after 1 year for both (female + male), female and male patients: \% ( \pm SD)

\begin{tabular}{|c|c|c|c|}
\hline & Placebo group & Strontium group & $p$ \\
\hline \multicolumn{4}{|c|}{$\Delta \mathrm{BMD}$ lumbar spine $(\%)$} \\
\hline Both & $3.94( \pm 4.49)$ & $9.94( \pm 6.33)$ & $<0.001$ \\
\hline Female & $4.98( \pm 4.28)$ & $10.71( \pm 6.18)$ & 0.005 \\
\hline Male & $1.73( \pm 4.42)$ & $8.99( \pm 6.63)$ & 0.009 \\
\hline \multicolumn{4}{|c|}{$\Delta$ BMD femoral neck $(\%)$} \\
\hline Both & $4.84( \pm 4.55)$ & $5.87( \pm 5.86)$ & 0.504 \\
\hline Female & $5.62( \pm 4.83)$ & $6.21( \pm 6.28)$ & 0.772 \\
\hline Male & $3.27( \pm 3.75)$ & $5.42( \pm 5.49)$ & 0.326 \\
\hline \multicolumn{4}{|c|}{$\Delta \mathrm{BMD} 1 / 3$ radius $(\%)$} \\
\hline Both & $0.00( \pm 3.36)$ & $0.42( \pm 4.06)$ & 0.690 \\
\hline Female & $0.75( \pm 3.00)$ & $0.40( \pm 4.80)$ & 0.810 \\
\hline Male & $-1.61( \pm 3.76)$ & $0.45( \pm 3.11)$ & 0.241 \\
\hline \multicolumn{4}{|c|}{$\Delta$ BMD MID radius $(\%)$} \\
\hline Both & $0.41( \pm 2.86)$ & $1.64( \pm 3.23)$ & 0.166 \\
\hline Female & $0.97( \pm 2.29)$ & $2.09( \pm 3.71)$ & 0.316 \\
\hline Male & $-0.78( \pm 3.75)$ & $1.08( \pm 2.57)$ & 0.271 \\
\hline \multicolumn{4}{|c|}{$\Delta$ BMD UD radius $(\%)$} \\
\hline Both & $1.84( \pm 5.76)$ & $3.02( \pm 5.86)$ & 0.474 \\
\hline Female & $2.90( \pm 5.37)$ & $4.37( \pm 6.14)$ & 0.482 \\
\hline Male & $-0.43( \pm 6.33)$ & $1.37( \pm 5.26)$ & 0.535 \\
\hline
\end{tabular}

$S D$ standard deviation, $B M D$ bone mineral density, $1 / 3$ radius one-third distal radius, MID radius mid-distal radius, UD radius ultradistal radius

was $68.9 \%$ in the SG and $77.3 \%$ in the PG. A statistically significant decline to $37.9 \%(p=0.034)$ was seen in the SG, whereas no relevant change was found in the PG $(72.7 \% ; p=1.000)$. Although statistically not significant anymore, there was a marked increase in patients with normal BMD values at the lumbar spine in the SG (from $31.0 \%$ at baseline to $62.1 \%$ after 1 year, $p=$ 0.061 ), whereas this increase was not found in the PG (from $22.7 \%$ at baseline to $27.6 \%$ after 1 year, $p=$ 0.734; Supplementary Data 2).

Initial osteoporosis and osteopenia at the femoral neck were identified in $89.3 \%$ and $68.2 \%$ of the patients in the SG and the $\mathrm{PG}$, respectively. After the 1-year follow-up period, there was a trend towards a decrease in osteoporotic/osteopenic patients in the SG with a $17.9 \%$ reduction to $71.4 \%(p=0.177)$. This reduction was not found in the PG $(66.7 \%$ after 1 year; $p=$ $1.000)$.

At the UD radius, the changes from 79.3 to $65.5 \%$ in the SG and from 81.8 to $73.9 \%$ in the PG did not prove to be statistically different ( $p=0.379$ and 0.722 , respectively). At the MID radius and $1 / 3$ radius, the percentages of osteoporosis and osteopenia remained nearly unchanged in both groups at more than $80 \%$ ( $p=1.000$ for both; $p=1.000$ and $p=0.491$, respectively).

\section{Change in biochemical parameters}

The PTH and $\mathrm{Ca}^{++}$levels decreased and phosphate increased as indices of successful pHPT treatment. Comparing the groups after 1 year, no statistically significant differences were seen except for the $\mathrm{Ca}^{++}$levels: the decrease in $\mathrm{Ca}^{++}$levels was significantly higher in the SG compared to the PG $(-0.22$ vs. $-0.12 \mathrm{mmol} / \mathrm{L} ; p=0.004$ ) (Table 3 ).

The markers of bone formation and markers of bone resorption decreased significantly in the SG and the PG (Table 3). Both parameters of the Wnt signaling pathway showed an increase: DKK-1 increased significantly in both groups and SOST showed a small increase in both groups that was only significant in the PG ( $p=0.043$ vs. $p=0.121$ in the SG; Table 3).

\section{Effects of preoperative PTH on biochemical markers of bone metabolism}

At baseline, the PTH levels were positively correlated with $\mathrm{Ca}^{++}(r=0.496 ; p<0.001)$, OC $(r=0.482 ; p<0.001)$, CTX $(r=0.420 ; p<0.005)$, and procollagen type $1 \mathrm{~N}$-terminal propeptide (P1NP; $r=0.332 ; p<0.05$ ), but not with BAP, OPG, RANKL, SOST, or DKK-1.

\section{Correlation of BMD increase with preoperative parameters}

In the PG, there was a strong and positive correlation between the preoperative levels of OC, P1NP, and CTX and the increase in lumbar-spine BMD (PG: $r=0.634, r=0.750, r=$ 0.634 , respectively). This correlation was weaker in the $\mathrm{SG}$ (SG: $r=0.413, r=0.329, r=0.329$, respectively) (Table 4). At the femoral neck, a relevant correlation between BAP and increase in BMD $(r=0.510)$ was only identified in the PG.

No significant correlation was seen between the preoperative levels of PTH, OPG, RANKL, SOST, or DKK-1 and gain in BMD at any site measured.

\section{Adverse events}

The intake of study medication did not induce any adverse events. In particular, no patient in either group developed cardiovascular disorders or thromboembolic complications during the study. No cases of vertebral or non-vertebral fractures occurred.

\section{Discussion}

This is the first prospective, randomized, double-blind trial to investigate the effect of anti-osteoporotic treatment on the 

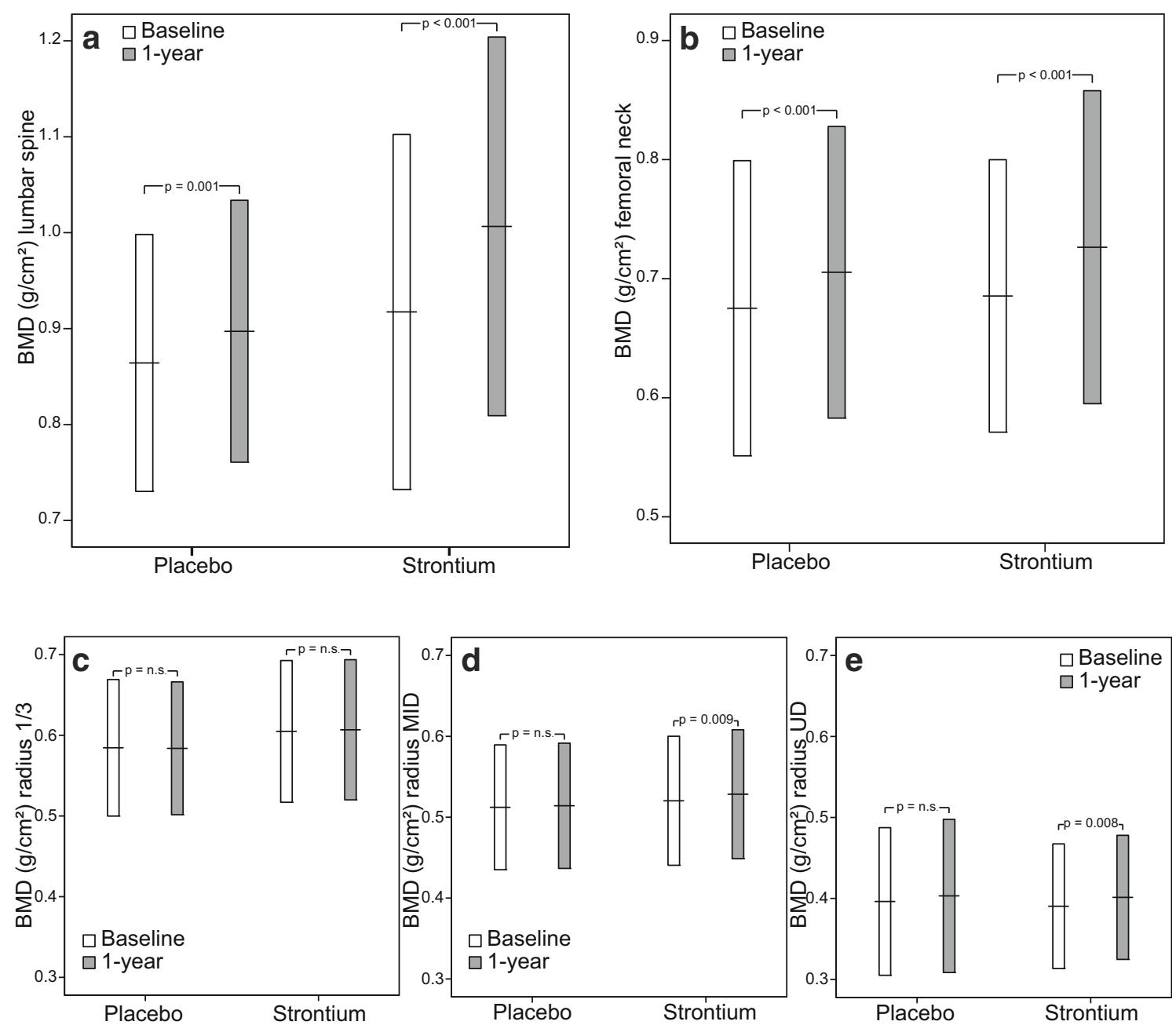

Fig. 2 Bone mineral density (BMD; mean $\pm 1 \mathrm{SD}$ ) at baseline and after 1 year in lumbar spine (a), femoral neck (b), one-third distal radius (1/3 radius, c), mid-distal radius (MID radius, $\mathbf{d}$ ), and ultradistal radius (UD radius, e)

postoperative course of BMD and bone metabolism after successful PTX, focusing only on patients with preoperatively advanced bone involvement (diagnosed osteoporosis or osteopenia). The rationale of this intervention was to enhance the speed and extent of bone density normalization in the early postoperative course. With intervention, the percentage of BMD increase at the lumbar spine was more than twofold higher in the treatment group than in the placebo group and the percentage of patients with osteopenia or osteoporosis declined from 69.0 to $37.9 \%$. The additional effect of $6 \%$ lumbar-spine BMD change (PG: 3.94\%; SG: 9.94\%) shown in this study was equal to the 1-year baseline change after SR intake found in patients with primary osteoporosis but without pHPT (postmenopausal women and men). This treatment effect has been seen to reduce both vertebral and non-vertebral fractures $[19,20,30]$. As the fracture risk is prolonged up to 10 or more years following successful PTX in patients with pHPT $[6,15,16]$, this effect seems preferable. The data presented here thus demonstrate that an anti-osteoporotic medication may additionally and positively influence bone remineralization, while producing similar effects as in patients without preceding PTX for pHPT. The effect on lumbar-spine BMD seems to be of even greater importance, as this site appears to be more strongly affected by pHPT [31, 32].

Although statistically not significant, a tendency towards a more pronounced gain in BMD at all sites was observed in females compared to males in either group (see Table 2). Especially for postmenopausal women who per se are at an elevated risk of fractures, any positive effect on bone stability seems important, since this trial showed that surgical cure of pHPT without additional treatment failed to reduce the proportion of patients with osteoporosis or osteopenia 1 year after PTX at any site in spite of adequate vitamin D and calcium supplementation. In a prospective and another retrospective trial, a further decrease in BMD was even documented in $15 \%$ to $31 \%[14,33]$.

The information on biochemical markers presented here offers a broad insight into postoperative changes following PTX. Basically, the levels of $\mathrm{Ca}^{++}$at diagnosis were only slightly elevated $(1.39$ and $1.41 \mathrm{mmol} / \mathrm{L}$ in the $\mathrm{SG}$ and $\mathrm{PG}$, 
Table 3 Biochemical parameters: intra-group changes (baseline to 1 year) and comparison between groups after 1 year

\begin{tabular}{|c|c|c|c|c|c|c|c|}
\hline & \multicolumn{3}{|l|}{ Placebo group } & \multicolumn{3}{|l|}{ Strontium group } & \multirow{2}{*}{$\begin{array}{l}\text { Between- } \\
\text { group } \\
\text { after } 1 \text { year } \\
p\end{array}$} \\
\hline & Baseline & 1 year & $p$ & Baseline & 1 year & $p$ & \\
\hline PTH (pg/mL) & $123.9(90.8 ; 162.2)$ & $36.2(15.9 ; 51.1)$ & $<0.001$ & $141.3(97.4 ; 162.9)$ & $29.5( \pm 23.5 ; 41.0)$ & $<0.001$ & 0.362 \\
\hline $\mathrm{Ca}++(\mathrm{mmol} / \mathrm{L})$ & $1.39(1.36 ; 1.43)$ & $1.25(1.21 ; 1.28)$ & $<0.001$ & $1.41(1.38 ; 1.50)$ & $1.22(1.18 ; 1.24)$ & $<0.001$ & 0.004 \\
\hline Phosphate (mmol/L) & $0.70(0.57 ; 0.83)$ & $1.03(0.90 ; 1.17)$ & $<0.001$ & $0.64(0.57 ; 0.74)$ & $1.04(0.95 ; 1.25)$ & $<0.001$ & 0.265 \\
\hline $25(\mathrm{OH}) \mathrm{D}(\mathrm{nmol} / \mathrm{L})$ & $38.9(26.8 ; 47.4)$ & $76.1(61.6 ; 84.3)$ & $<0.001$ & $39.8(29.8 ; 52.1)$ & $67.9(54.7 ; 83.4)$ & $<0.001$ & 0.352 \\
\hline $1,25(\mathrm{OH}) \mathrm{D}(\mathrm{nmol} / \mathrm{L})$ & $62.0(49.0 ; 77.0)$ & $46.0(40.0 ; 65.0)$ & 0.017 & $57.0(41.0 ; 73.0)$ & $57.0(41.0 ; 73.0)$ & 0.011 & 0.525 \\
\hline $\mathrm{BAP}(\mathrm{ng} / \mathrm{mL})$ & $20.4(14.6 ; 28.3)$ & $11.4(8.1 ; 12.4)$ & 0.01 & $15.9(10.8 ; 27.7)$ & $9.3(8.1 ; 12.1)$ & 0.001 & 0.410 \\
\hline $\mathrm{OC}(\mathrm{ng} / \mathrm{mL})$ & $41.8(22.8 ; 59.6)$ & $14.9(12.7 ; 20.8)$ & $<0.001$ & $33.2(25.2 ; 43.3)$ & $14.3(11.6 ; 17.8)$ & $<0.001$ & 0.519 \\
\hline CTX (ng/mL) & $0.84(0.42 ; 1.01)$ & $0.19(0.15 ; 0.28)$ & $<0.001$ & $0.63(0.52 ; 0.79)$ & $0.16(0.14 ; 0.24)$ & $<0.001$ & 0.366 \\
\hline P1NP (ng/mL) & $61.5(47.0 ; 89.0)$ & $24.0(20.0 ; 31.0)$ & $<0.001$ & $52.0(43.0 ; 74.5)$ & $24.0(22.0 ; 31.0)$ & $<0.001$ & 0.890 \\
\hline $24 \mathrm{~h} \mathrm{CrCl}(\mathrm{mL} / \mathrm{min})$ & $107.7(96.4 ; 132.8)$ & $91.4(78.9 ; 129.0)$ & 0.05 & $121.6(89.4 ; 161.5)$ & $112.6(90.6 ; 136.2)$ & 0.194 & 0.113 \\
\hline OPG (pmol/L) & $4.46(3.64 ; 5.64)$ & $4.97(3.57 ; 7.48)$ & 0.087 & $4.65(3.63 ; 5.47)$ & $5.05(3.38 ; 6.27)$ & 0.976 & 0.525 \\
\hline RANKL (pmol/L) & $0.87(0.51 ; 1.42)$ & $0.58(0.37 ; 1.35)$ & 0.465 & $0.74(0.52 ; 0.99)$ & $0.65(0.42 ; 0.94)$ & 0.068 & 1 \\
\hline SOST (pmol/L) & $19.63(15.55 ; 29.31)$ & $20.33(16.16 ; 41.01)$ & 0.043 & $20.84(14.85 ; 28.49)$ & $21.28(18.42 ; 29.01)$ & 0.121 & 0.920 \\
\hline DKK-1 (pmol/L) & $25.10(18.99 ; 35.69)$ & $34.07(20.06 ; 39.39)$ & 0.008 & $32.32(23.71 ; 41.04)$ & $34.40(29.39 ; 45.43)$ & 0.021 & 0.221 \\
\hline
\end{tabular}

PTH parathyroid hormone, $\mathrm{Ca}^{++}$ionized calcium, 25(OH)D 25-hydroxyvitamin D, 1,25(OH)D 1,25-dihydroxyvitamin D, BAP bone-specific alkaline phosphatase, $O C$ osteocalcin, $C T X$ CrossLaps, $P 1 N P$ procollagen type $1 \mathrm{~N}$-terminal propeptide, $24 \mathrm{~h} \mathrm{CrCl}$ measured 24-h creatinine clearance, $O P G$ osteoprotegerin, $R A N K L$ receptor activator of nuclear factor-kappa ligand, SOST sclerostin, DKK-1 Dickkopf-1

respectively; normal range $1.16-1.32 \mathrm{mmol} / \mathrm{L}$ ) as consequence to earlier diagnoses in Western countries due to screening programs with more frequently asymptomatic patients [31]. Nevertheless, alterations in markers of bone metabolism were documented in all patients demonstrating relevant bone involvement, albeit with a high level of variability (thus suggesting individual differences in pHPT-induced bone affection). The serum levels of CTX, a bone resorption marker, as well as those of the bone formation markers $\mathrm{OC}$ and P1NP significantly declined in all subjects at follow-up compared to baseline (Table 3). Additionally, the two antagonists of the Wnt signaling pathway ("antagonists" of bone formation) - SOST and DKK-1 - that have not yet been evaluated following PTX, slightly increased in both treatment groups over the 1-year follow-up. Both the increase in SOST and DKK-1 and the reduction of "classical" markers of bone metabolism suggest that PTX reduces bone resorption as well as bone formation. These findings are in line with our previous study, also showing reduced bone turnover after PTX surgery $[34,35]$. Therefore, it seems unreasonable to postoperatively apply a mainly antiresorptive treatment such as bisphosphonates that have even shown to bear potentially negative effects in pHPT-related bone involvement [36]. Although SR was limited in its use in 2017 (due to an advanced risk of thromboembolism and cardiovascular events), it seems reasonable to consider other anti-osteoporotic medications stimulating bone formation to improve BMD after PTX. Alternatively, the Wnt signaling pathway may be an interesting starting point for further investigation, as both
SOST and DKK-1 levels were seen to increase postoperatively in this trial. Romosozumab, an antibody against SOST, is a promising new therapeutic agent against osteoporosis, improving bone formation, and microarchitecture [25]. It was recently approved by the FDA and might be another potential pharmacological option. This assumption is in line with findings that expression of SOST in bone is enhanced after PTX for secondary (renal) HPT [37].

In addition to the effect of PTH in pHPT, low BMD may also be caused by such other factors as primary osteoporosis, especially in postmenopausal women. We therefore attempted to establish markers of bone metabolism that may potentially reflect bone involvement by pHPT. OC and CTX were strongly correlated (as strongly as $\mathrm{Ca}^{++}$) with preoperative PTH levels, and both markers, yet not PTH, showed a correlation with postoperative increase in BMD at the lumbar spine. These findings are in accordance with the study authored by Hansen et al., showing a correlation between increase in volumetric BMD and CTX (no data for OC) [38], but contradict the findings of Rolighed et al. who detected a positive association between preoperative PTH levels and postoperative BMD increase [39]. Preoperative biochemical markers may help to identify patients in whom a pronounced positive effect of successful PTX on postoperative BMD may be expected. They may also assist in differentiating such patients from those in whom primary osteoporosis and other factors may additionally strongly affect bone quality and who are less likely to improve after cure of $\mathrm{pHPT}$, thus requiring immediate additional therapy. 
Table 4 Correlation between absolute change in lumbar spine BMD and preoperative levels of markers of bone metabolism; $R$ : Spearman correlation index

\begin{tabular}{lcccccc}
\hline & \multicolumn{2}{l}{ Placebo group } & & \multicolumn{2}{l}{ Strontium group } \\
\cline { 2 - 3 } & Spearman index $(R)$ & $p$ & & Spearman index $(R)$ & $p$ \\
\hline Age & 0.085 & 0.706 & 0.139 & 0.473 \\
PTH & 0.292 & 0.187 & 0.232 & 0.226 \\
$\mathrm{Ca}^{++}$ & 0.292 & 0.187 & 0.256 & 0.180 \\
OC & 0.634 & 0.002 & 0.352 & 0.061 \\
P1NP & 0.750 & 0.001 & 0.413 & 0.029 \\
CTX & 0.634 & 0.002 & 0.274 & 0.159 \\
BAP & 0.229 & 0.413 & & 0.488 & 0.029 \\
OPG & -0.116 & 0.627 & -0.162 & 0.450 \\
RANKL & 0.600 & 0.400 & -0.800 & 0.200 \\
SOST & 0.098 & 0.682 & 0.079 & 0.713 \\
DKK-1 & -0.030 & 0.904 & -0.206 & 0.335 \\
\hline
\end{tabular}

$B M D$ bone mineral density, $P T H$ parathyroid hormone, $\mathrm{Ca}^{++}$ionized calcium, $O C$ osteocalcin, $P I N P$ procollagen type $1 \mathrm{~N}$-terminal propeptide, $C T X$ CrossLaps, $B A P$ bone-specific alkaline phosphatase, $O P G$ osteoprotegerin, $R A N K L$ receptor activator of nuclear factor-kappa ligand, SOST sclerostin, $D K K-1$ Dickkopf-1

Essentially, our investigation had several strengths: it was the first to investigate the effect of an anti-osteoporotic treatment immediately after successful PTX. Apart from its prospective, randomized, and double-blind design, the study population was very homogeneous, including only osteopenic and osteoporotic patients. Moreover, all patients were supplied with adequate standardized vitamin D and calcium doses, as shown to be important after PTX for pHPT [40].

A limitation of this trial is that SR was restricted in its use at the end of patient recruitment. Some of the measured effect of SR is likely caused by the overestimation of BMD in DXA scans of patients treated with SR (due to the higher atomic number of strontium compared to calcium [41]). However, even if $25 \%$ of the additional effect (approx. $6 \%$ ) in the SG was caused by overestimation of BMD, the increase would still be $3.5 \%$ higher than in the PG (3.94\% vs. SG: $7.47 \% ; p=0.01)$.

\section{Conclusion}

In conclusion, this randomized, double-blind, placebocontrolled trial indicated that the treatment of osteopenic or osteoporotic patients following PTX increases BMD mainly at the lumbar spine. The rationale of this trial was emphasized by the fact that without treatment, nearly all patients remained osteoporotic or at least osteopenic even with an adequate supply of vitamin D and calcium. In patients with high levels of OC and CTX, an increase in BMD is more likely than in those with low markers of bone metabolism. Thus, at least patients with osteoporosis/osteopenia with a lower probability of improvement after PTX should either be monitored closely for improvement in bone density or even receive bonespecific treatment immediately after PTX to reduce the risk of potential complications. As strontium ranelate was restricted in its use, other medications with positive effects on bone formation should be evaluated and the Wnt pathway may be another target for therapy.

Acknowledgments The authors wish to thank Mrs. Daniela Truzla for her important logistic support and patience.

Authors' contributions Study conception and design: MN, PP, KK, PR, BN. Acquisition of data: PR, AS, CS, BN, MN. Analysis and interpretation of data: MN, UF, PP, KK. Drafting manuscript: MN, UF, KK, PP. Critical revision of manuscript: MN, UF, KK, PP, BN, AS. Approving final version of manuscript: MN, UF, PR, AS, CS, BN, PP, KK.

Funding information Open access funding provided by Medical University of Vienna. This work was supported by the Austrian National Bank (OENB) Jubilee Fund, Project No. 13245. Both verum and placebo medication was provided by Servier.

\section{Compliance with ethical standards}

The study procedures of this double-blind, placebo-controlled, randomized trial were approved by the Ethics Committee of the Medical University of Vienna (EKNr: 2142008), the Austrian Agency for Health and Food Safety (Österreichische Agentur für Gesundheit und Ernährungssicherheit), ClinicalTrials.gov (identifier: NCT01222026), and European Union Drug Regulating Authorities Clinical Trials. All study participants gave written informed consent in accordance with the Declaration of Helsinki.

Conflict of interest PP has received research support and/or honoraria from Amgen $\mathrm{GmbH}$, Biomedica $\mathrm{GmbH}$, DePuySynthes, Fresenius Kabi Austria, Meda Pharma/Mylan GmbH, Shire Austria GmbH, TAmiRNA $\mathrm{GmbH}$, and UCB Pharma. All authors have declared that no competing financial interests or other conflicts of interest exist.

Ethical approval All procedures performed in this study were in accordance with the ethical standards of the institutional and national research committee and with the 1964 Helsinki Declaration and its later amendments.

Informed consent Informed consent was obtained from all individual participants included in the study.

Abbreviations SG, Strontium group; PG, Placebo group; pHPT, Primary hyperparathyroidism; BMD, Bone mineral density; PTX, Parathyroidectomy; $\mathrm{PTH}$, Parathyroid hormone; $\mathrm{Ca}^{++}$, Ionized calcium; 25(OH)D, 25-hydroxyvitamin $\mathrm{D} ; 1,25(\mathrm{OH}) \mathrm{D}, 1$, 25-dihydroxyvitamin $\mathrm{D}$; BAP, Bone-specific alkaline phosphatase; CTX, CrossLaps; P1NP, Procollagen type $1 \mathrm{~N}$-terminal propeptide; $24 \mathrm{~h} \mathrm{CrCl}$, Measured 24-h creatinine clearance; OPG, Osteoprotegerin; RANKL, Receptor activator of nuclear factor-kappa B ligand; DKK-1, Dickkopf-1; 1/3 radius, Onethird distal radius; MID radius, Mid-distal radius; UD radius, Ultradistal radius; DXA, Dual-energy X-ray absorption; OC, Osteocalcin; SD, Standard deviation; SOST, Sclerostin; SR, Strontium ranelate; OMIP, Open minimally invasive parathyroidectomy 
Open Access This article is distributed under the terms of the Creative Commons Attribution 4.0 International License (http:// creativecommons.org/licenses/by/4.0/), which permits unrestricted use, distribution, and reproduction in any medium, provided you give appropriate credit to the original author(s) and the source, provide a link to the Creative Commons license, and indicate if changes were made.

\section{References}

1. Siilin H, Rastad J, Ljunggren O, Lundgren E (2008) Disturbances of calcium homeostasis consistent with mild primary hyperparathyroidism in premenopausal women and associated morbidity. J Clin Endocrinol Metab 93(1):47-53. https://doi.org/10.1210/jc.20070600

2. Cusano NE, Rubin MR, Silva BC, Tay YD, Williams JM, Agarwal S, Omeragic B, Guo XE, Bilezikian JP (2018) Skeletal microstructure and estimated bone strength improve following parathyroidectomy in primary hyperparathyroidism. J Clin Endocrinol Metab 103(1):196-205. https://doi.org/10.1210/jc.2017-01932

3. Walker MD, Cong E, Lee JA, Kepley A, Zhang C, McMahon DJ, Silverberg SJ (2015) Vitamin D in primary hyperparathyroidism: effects on clinical, biochemical, and Densitometric presentation. J Clin Endocrinol Metab 100(9):3443-3451. https://doi.org/10.1210/ jc. 2015-2022

4. Viccica G, Cetani F, Vignali E, Miccoli M, Marcocci C (2017) Impact of vitamin D deficiency on the clinical and biochemical phenotype in women with sporadic primary hyperparathyroidism. Endocrine 55(1):256-265. https://doi.org/10.1007/s12020-0160931-8

5. Reid LJ, Muthukrishnan B, Patel D, Seckl JR, Gibb FW (2019) Predictors of nephrolithiasis, osteoporosis and mortality in primary hyperparathyroidism. J Clin Endocrinol Metab 104:3692-3700. https://doi.org/10.1210/jc.2018-02483

6. Vestergaard P, Mollerup CL, Frokjaer VG, Christiansen P, BlichertToft M, Mosekilde L (2000) Cohort study of risk of fracture before and after surgery for primary hyperparathyroidism. Bmj 321(7261): 598-602

7. De Geronimo S, Romagnoli E, Diacinti D, D'Erasmo E, Minisola S (2006) The risk of fractures in postmenopausal women with primary hyperparathyroidism. Eur J Endocrinol 155(3):415-420. https:// doi.org/10.1530/eje.1.02225

8. Khosla S, Melton LJ 3rd, Wermers RA, Crowson CS, O'Fallon W, Riggs B (1999) Primary hyperparathyroidism and the risk of fracture: a population-based study. J Bone Miner Res 14(10):17001707. https://doi.org/10.1359/jbmr.1999.14.10.1700

9. Eller-Vainicher C, Battista C, Guarnieri V, Muscarella S, Palmieri S, Salcuni AS, Guglielmi G, Corbetta S, Minisola S, Spada A, Hendy GN, Cole DE, Chiodini I, Scillitani A (2014) Factors associated with vertebral fracture risk in patients with primary hyperparathyroidism. Eur J Endocrinol 171(3):399-406. https://doi.org/10.1530/ EJE-14-0343

10. Bilezikian JP, Brandi ML, Eastell R, Silverberg SJ, Udelsman R, Marcocci C, Potts JT Jr (2014) Guidelines for the management of asymptomatic primary hyperparathyroidism: summary statement from the fourth international workshop. J Clin Endocrinol Metab 99(10):3561-3569. https://doi.org/10.1210/jc.2014-1413

11. Ambrogini E, Cetani F, Cianferotti L, Vignali E, Banti C, Viccica G, Oppo A, Miccoli P, Berti P, Bilezikian JP, Pinchera A, Marcocci C (2007) Surgery or surveillance for mild asymptomatic primary hyperparathyroidism: a prospective, randomized clinical trial. J Clin Endocrinol Metab 92(8):3114-3121. https://doi.org/10.1210/jc. 2007-0219
12. Rao DS, Phillips ER, Divine GW, Talpos GB (2004) Randomized controlled clinical trial of surgery versus no surgery in patients with mild asymptomatic primary hyperparathyroidism. J Clin Endocrinol Metab 89(11):5415-5422. https://doi.org/10.1210/jc. 2004-0028

13. Lundstam K, Heck A, Godang K, Mollerup C, Baranowski M, Pernow Y, Aas T, Hessman O, Rosen T, Nordenstrom J, Jansson S, Hellstrom M, Bollerslev J, Group SS (2017) Effect of surgery versus observation: skeletal 5 -year outcomes in a randomized trial of patients with primary HPT (the SIPH study). J Bone Miner Res 32(9):1907-1914. https://doi.org/10.1002/jbmr.3177

14. Sitges-Serra A, Garcia L, Prieto R, Pena MJ, Nogues X, Sancho JJ (2010) Effect of parathyroidectomy for primary hyperparathyroidism on bone mineral density in postmenopausal women. Br J Surg 97(7):1013-1019. https://doi.org/10.1002/bjs.7044

15. Lundstam K, Heck A, Mollerup C, Godang K, Baranowski M, Pernow Y, Varhaug JE, Hessman O, Rosen T, Nordenstrom J, Jansson S, Hellstrom M, Bollerslev J, Group SS (2015) Effects of parathyroidectomy versus observation on the development of vertebral fractures in mild primary hyperparathyroidism. J Clin Endocrinol Metab 100(4):1359-1367. https://doi.org/10.1210/jc. 2014-3441

16. Ramos L, Piedra M, Munoz P, Vazquez LA, Garcia-Unzueta MT, Montalban C, Amado JA (2019) Bone mineral density evolution and incidence of fractures in a cohort of patients with primary hyperparathyroidism treated with parathyroid surgery vs active surveillance during 6 years of follow-up. Endocrinol Diabetes Nutr 66(1):41-48. https://doi.org/10.1016/j.endinu.2018.05.010

17. Marie PJ (2006) Strontium ranelate: a physiological approach for optimizing bone formation and resorption. Bone 38(2 Suppl 1): S10-S14

18. Marie PJ (2007) Strontium ranelate: new insights into its dual mode of action. Bone 40:S5-S8

19. Meunier PJ, Roux C, Seeman E, Ortolani S, Badurski JE, Spector TD, Cannata J, Balogh A, Lemmel EM, Pors-Nielsen S, Rizzoli R, Genant HK, Reginster JY (2004) The effects of strontium ranelate on the risk of vertebral fracture in women with postmenopausal osteoporosis. N Engl J Med 350(5):459-468

20. Reginster JY, Seeman E, De Vernejoul MC, Adami S, Compston J, Phenekos C, Devogelaer JP, Curiel MD, Sawicki A, Goemaere S, Sorensen OH, Felsenberg D, Meunier PJ (2005) Strontium ranelate reduces the risk of nonvertebral fractures in postmenopausal women with osteoporosis: treatment of peripheral osteoporosis (TROPOS) study. J Clin Endocrinol Metab 90(5):2816-2822

21. O'Donnell S, Cranney A, Wells GA, Adachi JD, Reginster JY (2006) Strontium ranelate for preventing and treating postmenopausal osteoporosis. Cochrane Database Syst Rev 4:CD005326

22. Seeman E, Devogelaer JP, Lorenc RS, Spector T, Brixen K, Balogh A, Stucki G, Reginster JY (2007) Strontium ranelate reduces the risk of vertebral fractures in patients with osteopenia. J Bone Miner Res 10:1359

23. Ammann P (2006) Strontium ranelate: a physiological approach for an improved bone quality. Bone 38(2 Suppl 1):15-18

24. Bellido T, Ali AA, Gubrij I, Plotkin LI, Fu Q, O'Brien CA, Manolagas SC, Jilka RL (2005) Chronic elevation of parathyroid hormone in mice reduces expression of sclerostin by osteocytes: a novel mechanism for hormonal control of osteoblastogenesis. Endocrinology 146(11):4577-4583. https://doi.org/10.1210/en. 2005-0239

25. Chavassieux P, Chapurlat R, Portero-Muzy N, Roux JP, Garcia P, Brown JP, Libanati C, Boyce RW, Wang A, Grauer A (2019) Boneforming and Antiresorptive effects of Romosozumab in postmenopausal women with osteoporosis: bone Histomorphometry and microcomputed tomography analysis after 2 and 12 months of treatment. J Bone Miner Res. https://doi.org/10.1002/jbmr.3735 
26. Kanis JA, Melton LJ 3rd, Christiansen C, Johnston CC, Khaltaev N (1994) The diagnosis of osteoporosis. J Bone Miner Res 9(8):11371141

27. Bilezikian JP (2012) Primary hyperparathyroidism. Endocr Pract 18(5):781-790. https://doi.org/10.4158/EP12166.RA

28. Udelsman R, Akerstrom G, Biagini C, Duh QY, Miccoli P, Niederle $\mathrm{B}$, Tonelli $\mathrm{F}$ (2014) The surgical management of asymptomatic primary hyperparathyroidism: proceedings of the fourth international workshop. J Clin Endocrinol Metab 99(10):3595-3606. https://doi.org/10.1210/jc.2014-2000

29. Wilhelm SM, Wang TS, Ruan DT, Lee JA, Asa SL, Duh QY, Doherty GM, Herrera MF, Pasieka JL, Perrier ND, Silverberg SJ, Solorzano CC, Sturgeon C, Tublin ME, Udelsman R, Carty SE (2016) The American Association of Endocrine Surgeons Guidelines for definitive Management of Primary Hyperparathyroidism. JAMA Surg 151(10):959-968. https://doi. org/10.1001/jamasurg.2016.2310

30. Kaufman JM, Audran M, Bianchi G, Braga V, Diaz-Curiel M, Francis RM, Goemaere S, Josse R, Palacios S, Ringe JD, Felsenberg D, Boonen S (2013) Efficacy and safety of strontium ranelate in the treatment of osteoporosis in men. J Clin Endocrinol Metab 98(2):592-601. https://doi.org/10.1210/jc.2012-3048

31. Liu JM, Cusano NE, Silva BC, Zhao L, He XY, Tao B, Sun LH, Zhao HY, Fan WW, Romano ME, Ning G, Bilezikian JP (2013) Primary hyperparathyroidism: a tale of two cities revisited - New York and Shanghai. Bone Res 1(2):162-169. https://doi.org/10. 4248/BR201302005

32. Eller-Vainicher C, Filopanti M, Palmieri S, Ulivieri FM, Morelli V, Zhukouskaya VV, Cairoli E, Pino R, Naccarato A, Verga U, Scillitani A, Beck-Peccoz P, Chiodini I (2013) Bone quality, as measured by trabecular bone score, in patients with primary hyperparathyroidism. Eur J Endocrinol 169(2):155-162. https://doi.org/ 10.1530/EJE-13-0305

33. Dy BM, Grant CS, Wermers RA, Kearns AE, Huebner M, Harmsen WS, Thompson GB, Farley DR, Richards ML (2012) Changes in bone mineral density after surgical intervention for primary hyperparathyroidism. Surgery 152(6):1051-1058. https://doi.org/10. 1016/j.surg.2012.08.015

34. Kerschan-Schindl K (2013) Bone turnover in hyperparathyroidism. Wien Med Wochenschr 163(17-18):391-396. https://doi.org/10. 1007/s10354-012-0125-9
35. Kerschan-Schindl K, Riss P, Krestan C, Rauner M, Bieglmayer C, Gleiss A, Fialka-Moser V, Niederle B, Pietschmann P (2012) Bone metabolism in patients with primary hyperparathyroidism before and after surgery. Horm Metab Res 44(6):476-481. https://doi. org $/ 10.1055 / \mathrm{s}-0032-1308998$

36. Yeh MW, Zhou H, Adams AL, Ituarte PH, Li N, Liu IL, Haigh PI (2016) The relationship of parathyroidectomy and bisphosphonates with fracture risk in primary hyperparathyroidism: an observational study. Ann Intern Med 164(11):715-723. https://doi.org/10.7326/ M15-1232

37. Pires GO, Vieira IO, Hernandes FR, Teixeira AL, Oliveira IB, Dominguez WV, Dos Reis LM, Montenegro FM, Moyses RM, Carvalho AB, Jorgetti V (2019) Effects of parathyroidectomy on the biology of bone tissue in patients with chronic kidney disease and secondary hyperparathyroidism. Bone 121:277-283. https:// doi.org/10.1016/j.bone.2019.01.029

38. Hansen S, Hauge EM, Rasmussen L, Jensen JE, Brixen K (2012) Parathyroidectomy improves bone geometry and microarchitecture in female patients with primary hyperparathyroidism: a one-year prospective controlled study using high-resolution peripheral quantitative computed tomography. J Bone Miner Res 27(5):1150-1158. https://doi.org/10.1002/jbmr.1540

39. Rolighed L, Vestergaard P, Heickendorff L, Sikjaer T, Rejnmark L, Mosekilde L, Christiansen P (2013) BMD improvements after operation for primary hyperparathyroidism. Langenbeck's Arch Surg 398(1):113-120. https://doi.org/10.1007/s00423-012-1026-5

40. Kaderli RM, Riss P, Dunkler D, Pietschmann P, Selberherr A, Scheuba C, Niederle B (2018) The impact of vitamin D status on hungry bone syndrome after surgery for primary hyperparathyroidism. Eur J Endocrinol 178(1):1-9. https://doi.org/10.1530/EJE-170416

41. Blake GM, Lewiecki EM, Kendler DL, Fogelman I (2007) A review of strontium ranelate and its effect on DXA scans. J Clin Densitom 10(2):113-119. https://doi.org/10.1016/j.jocd.2007.01. 002

Publisher's note Springer Nature remains neutral with regard to jurisdictional claims in published maps and institutional affiliations. 